UDC 347.41

LBC 67.9.304.2

\title{
SECURITY DEPOSIT AS MEANS OF SECURING NON-CONTRACTUAL PROTECTIVE OBLIGATIONS
}

\author{
Victoriya V. Akinfieva \\ Perm State National Research University, Perm, Russian Federation
}

Introduction: the article is dedicated to the possibility of using a new means of securing the fulfillment of an obligation, i.e. the security deposit for securing obligations arising from the infliction of harm or from unjust enrichment. Purpose: to prove the possibility and perspectivity of using the security deposit for securing noncontractual protective obligations and to reveal the specific features of such a usage as compared to securing contractual obligations. Methods: along with the general scientific methods of scientific cognition (dialectical, systematic, functional, formal and logical), the specific juridical methods of legal comparison and legal modelling are used. Results: non-contractual protective obligations can only be the ground for creating a security obligation if accompanied by the compromise agreement of the parties; nevertheless, they can be independent securing objects. The dispositive method of the civil law regulation allows making agreements on securing a non-contractual obligation both before and after the creation of the obligation. Conclusions: the use of a security deposit in binding non-contractual protective legal relations can enhance the role of the private civil law enforcement and improve the efficiency of applying non-jurisdictional forms of redress for infringed civil rights.

Key words: security deposit, methods of securing the fulfillment of an obligation, securing legal relation, non-contractual obligations, security deposit agreement.

УДК 347.41

ББК 67.9.304.2

\section{ОБЕСПЕЧИТЕЛЬНЫЙ ПЛАТЕЖ КАК СПОСОБ ОБЕСПЕЧЕНИЯ ВНЕДОГОВОРНЫХ ОХРАНИТЕЛЬНЫХ ОБЯЗАТЕЛЬСТВ}

\author{
Виктория Вадимовна Акинфиева \\ Пермский государственный национальный исследовательский университет, \\ г. Пермь, Российская Федерация
}

Введение: статья посвящена возможности использования нового способа обеспечения исполнения обязательств - обеспечительного платежа для обеспечения обязательств, возникающих из причинения вреда или из неосновательного обогащения. Цель: доказать возможность и перспективность применения обеспечительного платежа для обеспечения внедоговорных охранительных обязательств и выявить особенности такого применения по сравнению с обеспечением договорных обязательств. Методы: помимо общенаучных методов научного познания (диалектического, системного, функционального, формально-логического) использованы специально-юридические методы правового сравнения и правового моделирования. Результаты: внедоговорные охранительные обязательства только вместе с соглашением сторон могут выступать в качестве основания возникновения обеспечительного обязательства, однако при этом могут являться самостоятельными объектами обеспечения. Диспозитивный метод гражданско-правового регулирования позволяет заключать соглашение об обеспечении внедоговорного обязательства как до, так и после его возникновения. Выводы: использование обеспечительного платежа в обязательственных внедоговорных охранительных правоотношениях способно повысить роль частного гражданско-правового принуждения и эффективность применения неюрисдикционных форм защиты нарушенных гражданских прав. 
Ключевые слова: обеспечительный платеж, способы обеспечения исполнения обязательств, обеспечительное правоотношение, внедоговорные обязательства, договорные обязательства, соглашение об обеспечительном платеже.

\section{Введение}

В результате реформирования российского обязательственного права система способов обеспечения исполнения обязательств пополнилась обеспечительным платежом, который ранее был не известен гражданскому законодательству.

Следует отметить, что обеспечительный платеж для гражданского оборота не является новым, он часто использовался в качестве непоименованного способа обеспечения, особенно при заключении предварительных договоров, и давно нашел устойчивое применение в практике. В этом отношении прав Д.А. Торкин, заметивший, что «ни один из поименованных в законе способов обеспечения исполнения обязательств не возник в результате научного предложения» [9, с. 44]. Думается, что это справедливо и для обеспечительного платежа, выработанного деловой и общегражданской практикой до момента своей позитивации.

Представители юридической науки уже дали положительную оценку рассматриваемой новелле. Так, В.Г. Голубцов нормативное оформление обеспечительного платежа назвал «одной из прогрессивных новелл» [2, с. 48] гражданского законодательства. А.А. Диденко высказал мнение о том, что «появление в ГК РФ отдельной нормы, регулирующей применение обеспечительного платежа, будет способствовать более широкому распространению данного вида обеспечения исполнения обязательств» [3, с. 65].

В соответствии со ст. 381.1 ГК РФ денежное обязательство, в том числе обязанность возместить убытки или уплатить неустойку в случае нарушения договора, и обязательство, возникшее по основаниям, предусмотренным п. 2 ст. 1062 ГК РФ, по соглашению сторон могут быть обеспечены внесением одной из сторон в пользу другой стороны определенной денежной суммы (обеспечительный платеж). Обеспечительным платежом может быть обеспечено обязательство, которое возникнет в будущем.
То, что договорное обязательство может быть обеспечено обеспечительным платежом, сомнений не вызывает, об этом свидетельствует и доктрина, и правоприменительная практика. Однако может ли обеспечительный платеж обеспечивать исполнение внедоговорных охранительных обязательств, которые в большинстве своем также являются денежными? Эта проблема уже поставлена в цивилистике: «...остается открытым вопрос о том, может ли обеспечительный платеж обеспечить внедоговорное обязательство, например, вследствие причинения вреда или неосновательного обогащения» [4, с. 25].

\section{Соотношение внедоговорных и договорных обязательств как объектов обеспечения}

Важно подчеркнуть, что, несомненно, ни деликт, ни неосновательное обогащение не могут быть самостоятельными основаниями возникновения обеспечительного отношения, поскольку таким основанием является соглашение сторон, что следует из буквального толкования ст. 381.1 ГК РФ. Но, на наш взгляд, внедоговорные обязательства могут выступать в качестве обязательств, обеспечиваемblx обеспечительным платежом.

Более того, представляется, что именно обеспечительный платеж способен достаточно эффективно удовлетворять обеспечительный интерес кредитора, стимулируя надлежащее исполнение обязательств, возникших вследствие причинения вреда и из неосновательного обогащения.

Несмотря на то что договорное и внедоговорное обязательство имеет одну и ту же гражданско-правовую юридическую форму обязательство, важно учитывать разный механизм их возникновения, от которого зависят особенности использования обеспечительного платежа.

Современное российское гражданское право не дает понятия деликтного обязательства. Законодатель определил подобного вида обязательства следующим образом: вред, 
причиненный личности или имуществу гражданина, а также вред, причиненный имуществу юридического лица, подлежит возмещению в полном объеме лицом, причинившим вред (п. 1 ст. 1064 ГК РФ).

Г.Ф. Шершеневич понимал под ним недозволенное действие, нарушающее чужое субъективное право причинением имущественного вреда. Вследствие такого факта между лицом, причинившим вред, и лицом, потерпевшим вред, устанавливается отношение, в силу которого первый обязывается возместить понесенные вторым имущественные убытки [10, с. 392].

Обязательства из неосновательного обогащения не являются разновидностью гражданско-правовой ответственности, которая всегда является следствием противоправного поведения - правонарушения [6, с. 97]. Определение такого обязательства содержится в ст. 1102 ГК РФ: «лицо, которое без установленных законом, иными правовыми актами или сделкой оснований приобрело или сберегло имущество (приобретатель) за счет другого лица (потерпевшего), обязано возвратить последнему неосновательно приобретенное или сбереженное имущество (неосновательное обогащение)».

С деликтами их роднит внедоговорная природа: «В п. 2 ст. 1102 ГК РФ ... закрепляется необходимость для квалификации отношений как обязательства вследствие неосновательного обогащения, наличия неосновательного приобретения или сбережения имущества без соответствующего правового основания, то есть объективно-противоправного результата» $[5$, с. 24$]$.

Внедоговорные обязательства, в отличие от большинства договорных, являются простыми, не взаимными, в них всегда единственному праву требования одного лица (кредитора) противостоит единственная обязанность другого лица - должника (возместить убытки, вернуть неосновательное обогащение). На это обстоятельство обращается внимание в юридической литературе: «договорные обязательства в основном двусторонние (взаимные). Деликтные же обязательства всегда односторонние, так как праву потерпевшего требовать возмещения вреда противостоит обязанность должника возместить вред в полном объеме» [7, с. 16].
Внедоговорные обязательства возникают из факта нарушения субъективного права кредитора, который не состоит в договорных отношениях с должником (нарушителем права). Во внедоговорных обязательствах должник нарушает не заранее предусмотренную договором обязанность, а предусмотренную законом обязанность пассивного типа - воздержаться от нарушения прав других лиц.

\section{Соглашение об обеспечении} внедоговорного охранительного обязательства: темпоральный аспект

В договорном обязательстве стороны заранее известны, соответственно сторона, у которой возникает денежное обязательство перед другой стороной, в том числе возместить убытки или уплатить неустойку в случае нарушения своей обязанности, может осуществить обеспечительный платеж в пользу другой заранее известной стороны по договору.

Внедоговорные обязательства всегда возникают неожиданно для обеих сторон, помимо их воли. Стороны во внедоговорных обязательствах чаще всего заранее друг другу неизвестны. Однако возможны ситуации, при которых одно лицо может заранее предвидеть возникновение потенциально возможного внедоговорного вреда в результате действий другого лица, например, когда сосед начал сложный ремонт и т. п. Возможно и такое же предвидение наступления неосновательного обогащения у определенного лица.

Диспозитивная природа гражданско-правовых отношений и свобода договорных связей позволяет и в таком случае заключить соглашение о передаче обеспечительного платежа в обеспечение исполнения деликтного или кондикционного обязательства, способного возникнуть в будущем. О.Г. Ершов по этому поводу пишет: «Если принять за основу один из базовых принципов гражданского права дозволительной направленности, когда разрешено все, что не запрещено, - то препятствий в этой части не наблюдается. Более того, если изначально возможно обеспечение сумм неустойки и убытков, основанием возникновения которых является гражданское правонарушение, то обеспечивать заранее и внедоговорные обязательства, возникающие в связи 
с правонарушением, вполне возможно. Это также согласуется с правилами о том, что обеспечительный платеж может обеспечить обязательство, которое возникнет в будущем (п. 1 ст. 381.1 ГК РФ)» [4, с. 25$]$.

В большинстве же случаев никаких «предварительных» обеспечительных отношений между кредитором и должником в плане внедоговорных обязательств не существует. Кроме того, подобное обязательство чаще всего является «спорным», должник не желает в добровольном порядке его исполнять; в таких ситуациях никакие обеспечительные механизмы не работают, приходится обращаться к инструментам государственного принуждения, в том числе исполнительного производства.

При этом нельзя исключать варианты добровольного исполнения уже возникших внедоговорных охранительных обязательств. Так, А. Розенталь отмечает: «...ГК РФ в главе об обязательствах вследствие причиненного вреда содержит целый ряд норм, допускающих определение размера соответствующих выплат по соглашению сторон. Следовательно, весьма допустимым имеет место соглашение, в силу которого одно лицо - причинитель вреда обязуется возместить другому лицу - потерпевшему причиненный вред по основаниям и в размере, установленных в таком соглашении» [8].

В возможности использования удовлетворения интересов кредитора в неюрисдикционной форме заключена важнейшая черта гражданско-правового принуждения [11, c. 216-218]. При этом стороны внедоговорного обязательства могут заключить и соглашение об обеспечении его исполнения при помощи передачи обеспечительного платежа.

\section{Содержание внедоговорного охранительного обязательства как условие обеспечения обеспечительным платежом}

Важно отметить и то, что обеспечительный платеж имеет смысл использовать, только если соглашения сторон предусмотрели исполнение деликтного или кондикционного обязательства в натуре. В частности, согласно ст. 1082 ГК РФ способами возмещения вреда являются либо возмещение в натуре, либо возмещение убытков. Если же содержанием соглашения сторон рассматриваемых обязательств является обязанность возместить убытки, то передача обеспечительного платежа становится бессмысленной.

К примеру, истец обратился в суд с иском к ответчику о взыскании ущерба, причиненного в результате дорожно-транспортного происшествия, также истец указал на неисполнение ответчиком соглашения о возмещении вреда, заключенного сторонами спора, в соответствии с которым ответчик компенсирует истцу причиненный вред. Суд, установив обстоятельства дела, а также вину ответчика, приняв во внимание буквальное значение содержащихся в соглашении слов и выражений, установив факт его неисполнения, пришел к выводу об обоснованности заявленных требований, иск удовлетворил [1]. Из анализа приведенного судебного акта следует, что после возникновения обязательства вследствие причинения вреда между кредитором и должником было заключено соглашение о механизме его исполнения и последствиях его неисполнения.

Несмотря на то что стороны рассматриваемого спора не использовали в соглашении способы обеспечения исполнения деликтного обязательства, в этой и подобных ситуациях они могли бы согласовать передачу обеспечительного платежа, указав, например, что должник передает кредитору сумму, равную, как последний предполагает, размеру причиненного ущерба, до того момента, когда должник произведет ремонт поврежденного имущества. В том случае, если кредитора устроит качество произведенного ремонта, сумма, переданная ему в качестве обеспечения исполнения обязательства, возвращается им должнику полностью. В противном случае имущественные требования кредитора могут быть удовлетворены из суммы обеспечительного платежа. Если бы стороны в соглашении указали, что должник возмещает убытки в определенном размере, то любой платеж кредитору в данном случае выполнял бы только платежную функцию и являлся, по сути, авансом.

\section{Выводы}

Таким образом, обеспечительный платеж может быть использован как способ 
обеспечения обязательств, возникших вследствие причинения вреда или неосновательного обогащения.

Причинение вреда или неосновательное обогащение не могут выступать в качестве основания для возникновения обеспечительного обязательства, однако в совокупности с соглашением сторон могут быть элементами юридического состава, влекущего возникновение обязательства, основанного на обеспечительном платеже. Такое соглашение может быть заключено как до, так и после причинения вреда или возникновения неосновательного обогащения.

На наш взгляд, использование субъектами гражданского права обеспечительного платежа в качестве обеспечения исполнения внедоговорного обязательства способно увеличить роль частного гражданско-правового принуждения и расширить возможности самостоятельного и инициативного использования обеспечительных инструментов. В связи с этим полагаем нелишним нормативное указание в ст. 381.1 ГК РФ на то, что обеспечительным платежом может быть обеспечено обязательство вследствие причинения вреда и обязательство из неосновательного обогащения.

\section{СПИСОК ЛИТЕРАТУРЫ}

1. Апелляционное определение Нижегородского областного суда от 26 авг. 2014 г. по делу № 33-7182. Доступ из справ.-правовой системы «КонсультантПлюс».

2. Голубцов, В. Г. Обеспечительный платеж в системе способов обеспечения гражданско-правовых обязательств / В. Г. Голубцов // Законность и правопорядок в современном обществе. - 2016. № 29. - C. $47-52$.

3. Диденко, А. А. Новые правила ГК РФ о способах обеспечения исполнения обязательств / А. А. Диденко// Власть закона. - 2016. - № 1. - С. 63-72.

4. Ершов, О. Г. Обеспечительный платеж и смежные юридические конструкции / О. Г. Ершов // Вестник Омской юридической академии. - 2016. № 2. - C. 24-27.

5. Корнилова, Н. В. Понятие и условия возникновения обязательств вследствие неосновательного обогащения / Н. В. Корнилова // Юрист. 2004. -№ 7. - C. 21-24.

6. Кузнецова, О. А. Гражданско-правовая ответственность: методологические проблемы иссле- дования / О. А. Кузнецова // Экономика. Предпринимательство. Окружающая среда. - 2016. - Т. 3, № 67. - C. 94-100.

7. Поляков, И. Н. Ответственность по обязательствам вследствие причинения вреда / И. Н. Поляков. - М. : Городец, 1998. - 172 с.

8. Розенталь, А. Приступим к отступному / А. Розенталь // Бизнес-адвокат. - 2000. - № 2.

9. Торкин, Д. А. Непоименованные способы обеспечения обязательств : дис. ... канд. юрид. наук / Торкин Дмитрий Александрович. - Тюмень, 2005. $-182 \mathrm{c}$.

10. Шершеневич, Г. Ф. Учебник русского гражданского права / Г. Ф. Шершеневич. - М. : Спарк, 1995. $-556 \mathrm{c}$.

11. Яковлев, В. Ф. Принуждение в гражданском праве / В. Ф. Яковлев // Проблемы современного гражданского права : сб. ст. - М. : Городец, 2000. - C. 210-222.

\section{REFERENCES}

1. Apellyatsionnoe opredelenie Nizhegorodskogo oblastnogo suda ot 26 avg. 2014 g. po delu № 33-7182 [The Appeal of the Decision of Nizhny Novgorod Regional Appeal Court of August 26, 2014 on Case no. 33-7182]. Access from Reference Legal System "KonsultantPlyus".

2. Golubtsov V.G. Obespechitelnyy platezh v sisteme sposobov obespecheniya grazhdanskopravovykh obyazatelstv [Security Payment in the System of Ways to Ensure Civil Obligations]. Zakonnost i pravoporyadok $v$ sovremennom obshchestve, 2016, no. 29, pp. 47-52.

3. Didenko A.A. Novye pravila GK RF o sposobakh obespecheniya ispolneniya obyazatelstv [New Rules of the Civil Code of the Russian Federation on the Ways to Ensure the Fulfillment of Obligations]. Vlast zakona, 2016, no. 1, pp. 63-72.

4. Ershov O.G. Obespechitelnyy platezh i smezhnye yuridicheskie konstruktsii [Security Deposit and Related Legal Constructions]. Vestnik Omskoy yuridicheskoy akademii, 2016, no. 2, pp. 24-27.

5. Kornilova N.V. Ponyatie i usloviya vozniknoveniya obyazatelstv vsledstvie neosnovatelnogo obogashcheniya [The Concept and Conditions for the Emergence of Obligations due to Unjust Enrichment]. Yurist, 2004, no. 7, pp. 21-24.

6. Kuznetsova O.A. Grazhdansko-pravovaya otvetstvennost: metodologicheskie problemy issledovaniya [Civil Liability: Methodological Problems of Research]. Ekonomika. Predprinimatelstvo. Okruzhayushchaya sreda, 2016, vol. 3, no. 67, pp. 94-100.

7. Polyakov I.N. Otvetstvennost po obyazatelstvam vsledstvie prichineniya vreda 
[Responsibility for Obligations as a Result of Causing Harm]. Moscow, Gorodets Publ., 1998. 172 p.

8. Rozental A. Pristupim k otstupnomu [Let's Get to Payoff]. Biznes-advokat, 2000, no. 2.

9. Torkin D.A. Nepoimenovannye sposoby obespecheniya obyazatelstv: dis. ... kand. yurid. nauk [Unnamed Methods of Ensuring Obligations. Cand. jurid. sci. diss.]. Tyumen, 2005. $182 \mathrm{p}$.
10. Shershenevich G.F. Uchebnik russkogo grazhdanskogo prava [Textbook of Russian Civil Law]. Moscow, Spark Publ., 1995. 556 p.

11. Yakovlev V.F. Prinuzhdenie v grazhdanskom prave [Coercion in Civil Law]. Problemy sovremennogo grazhdanskogo prava: sb. st. [Problems of Contemporary Civil Law: Collected Articles]. Moscow, Gorodets Publ., 2000, pp. 210-222.

\section{Information about the Author}

Victoriya V. Akinfieva, Senior Lecturer, Department of Entrepreneurial Law, Civil and Arbitration Procedure, Perm State National Research University, Bukireva St., 15, 614990 Perm, Russian Federation, vakinfieva@yandex.ru.

\section{Информация об авторе}

Виктория Вадимовна Акинфиева, старший преподаватель кафедры предпринимательского права, гражданского и арбитражного процесса, Пермский государственный национальный исследовательский университет, ул. Букирева, 15, 614990 г. Пермь, Российская Федерация, vakinfieva@yandex.ru. 